\title{
Rodletless, a new Aspergillus developmental mutant induced by directed gene inactivation
}

\author{
Mary A. Stringer, ${ }^{1}$ Ralph A. Dean, ${ }^{1,2}$ Tommy C. Sewall, ${ }^{3,4}$ and William E. Timberlake ${ }^{1,3}$ \\ ${ }^{1}$ Department of Genetics and ${ }^{3}$ Department of Plant Pathology, University of Georgia, Athens, Georgia 30602 USA
}

The Aspergillus nidulans CAN41 transcription unit is activated by the brlA regulatory gene early during development of the asexual reproductive apparatus, the conidiophore. Disruption of CAN41 results in a novel mutant phenotype in which conidiophore cells and spores lack an external wall layer, the rodlet layer, making them less hydrophobic than in the wild type and leading to inefficient spore dispersal. The rodletless mutation defines a new locus on chromosome III, rodA. rodA encodes a small, moderately hydrophobic polypeptide containing 8 cysteines arranged in a pattern similar to that observed in three hydrophobic cell wall proteins from the Holobasidiomycete Schizophyllum commune. We propose that the Aspergillus and Schizophyllum 8-cysteine polypeptides define a class of secreted, hydrophobic, fungal cell wall proteins that are important in the formation and function of aerial structures such as conidiophores and mushrooms.

[Key Words: Aspergillus nidulans; sporulation; spore wall; rodlet layer; reverse genetics]

Received April 1, 1991; revised version accepted May 1, 1991.

The production of asexual spores (conidia) by the filamentous fungus Aspergillus nidulans provides an example of programmed development that has been characterized by both genetic and molecular methods (for review, see Timberlake 1990). Conidiation initiates in vegetative colonies following the achievement of developmental competence when environmental conditions are favorable (Axelrod et al. 1973) and is marked by the differentiation of specialized foot cells that give rise to aerial, multicellular, spore-bearing conidiophores (Oliver 1972; Mims et al. 1988). Martinelli and Clutterbuck (1971) estimated that 45-150 loci contribute specifically to spore production by comparing the frequency of developmental mutations with the frequency of selected, nondevelopmental mutations. Approximately 30 developmental mutants have been described in some detail (Clutterbuck 1987). About one-third of these are defective in the initiation of sporulation, one-third produce abnormally pigmented or nonmaturing spores, and onethird are altered in conidiophore morphology.

In contrast to genetic estimates, molecular analyses suggest the involvement of a much larger number of genes. Approximately 1200 unique mRNAs accumulate preferentially during conidiation, $\sim 200$ of which occur in mature spores (Timberlake 1980; Zimmermann et al. 1980; Orr and Timberlake 1982). A large collection of

Present addresses: ${ }^{2}$ Department of Plant Pathology and Physiology, Clemson University, Clemson, South Carolina 29634 USA; ${ }^{4}$ Department of Biology, Texas A\&M University, College Station, Texas 77843 USA.
cDNA and genomic clones corresponding to developmentally regulated transcripts has been made (Zimmermann et al. 1980; Boylan et al. 1987). These clones have been characterized by the compilation of RNA accumulation profiles in wild-type and conidiation-defective mutants and in strains where developmental regulatory genes have been artificially activated in vegetative cells (Boylan et al. 1987; Adams et al. 1988; Mirabito et al. 1989; Timberlake 1990; Marshall and Timberlake 1991).

The disparity between the number of genes known to be specifically activated during conidiation and the number of developmental mutants leads to the question of what role, if any, conidiation-specific genes have in development. To begin addressing this question, we have chosen one cDNA clone, pCAN41, for detailed analysis: The transcript appears early during development, and its accumulation requires the early regulatory gene $b r l A$ but not the later regulatory genes $a b a A$ and wet $A$ (Boylan et al. 1987; Adams et al. 1988; Mirabito et al. 1989; Marshall and Timberlake 1991). In this study we have used DNA sequence comparisons and directed mutagenesis to determine the role in sporulation of the gene corresponding to pCAN41. Our results show that CAN41 identifies a new developmental locus that is essential for the formation of the outer hydrophobic wall layer of conidiophore cells and spores, the rodlet layer. We have named this gene rodA, for rodletless, and propose that it is a member of a class of genes encoding secreted fungal cell wall proteins that are important in the morphogenesis of hydrophobic, aerial hyphae and reproductive structures. 


\section{Results \\ Developmental regulation of CAN41}

pCAN41 was selected in a screen for developmentally regulated $A$. nidulans cDNA clones (Boylan et al. 1987). The pattern of CAN41 transcript accumulation is shown in Figure 1. The transcript was present at low or undetectable levels in vegetative cells (hyphae) and mature conidia but at readily detectable levels in developmentally induced cultures, which contain hyphae, conidiophores, and conidia. These results imply that the CAN41 transcript accumulates preferentially in conidiophores. The CAN41 transcript failed to accumulate in a developmentally induced culture of a mutant strain lacking an active brlA early regulatory gene (see Timberlake 1990 ). In contrast, the transcript accumulated to apparently wild-type levels in developmentally induced cultures of mutant strains lacking the later-acting $a b a A$ and wet $A$ regulatory genes. Thus, in the normal sequence of development, CAN41 expression is brlA dependent, but $a b a A$ and wet $A$ independent. Finally, the CAN41 transcript accumulated in hyphae of a strain containing the brlA gene fused to the promoter from the alcohol dehydrogenase I gene alcA (Adams et al. 1988) when the strain was grown on an inducing carbon source (threonine) but not when the strain was grown on a repressive carbon source (glucose). Transcript accumulation under these conditions was also independent of the action of $a b a A$ and wet $A$ and any regulatory genes acting upstream of $b r l A$, demonstrating that $\operatorname{brl} A$ expression is sufficient for the induction of CAN41 transcript accumulation.

\section{Transcriptional organization and sequence of CAN41}

pCAN41 was used to identify a genomic clone, and the CAN41-coding region was localized to the $3.5-\mathrm{kb}$ EcoRIXhol fragment shown in Figure $2 \mathrm{~A}$. The sequences of the cDNA and corresponding gene and flanking regions were determined and are given in Figure 2B. The CAN41 gene consists of three exons predicted to encode a 157-aminoacid residue, moderately hydrophobic $144 \%$ hydrophobic residues: A, F, I, L, M, P, and V) polypeptide. This polypeptide contains 8 cysteine residues, a single potential $N$-glycosylation site (Devereux et al. 1984), a highly hydrophobic amino-terminal sequence (see Fig. 8B, below), and has a net charge of -3 at $\mathrm{pH} 7$. RodA has significant sequence similarity to three extracellular polypeptides from the wood-rotting fungus Schizophyllum commune (see Discussion; Schuren and Wessels 1990). No other significant sequence similarities were identified in computer-assisted searches of the GenBank, EMBL, and NBRF data bases.

\section{Inactivation of CAN41 leads to loss of the rodlet layer}

To investigate the function of CAN41, we utilized the strategy outlined in Figure $3 \mathrm{~A}$ to inactivate the gene (Timberlake and Marshall 1989). Both haploid and diploid strains were transformed, as a heterozygous diploid would enable mutation recovery if CAN41 inactivation were recessively lethal. A screen of transformants by Southern blot analysis identified CAN41 deletion events among both haploids and diploids. Thus, CAN41 inactivation is not lethal. Transformants TMSO15 (haploid) and TMS017 (diploid) were chosen for further study. Figure 3B shows that CAN41 had been replaced by the $\arg B$ selective marker in the haploid. In the diploid, one copy of CAN41 had been replaced by the selective marker and one copy remained wild type.

Haploid CAN41 disruptants displayed a consistent mutant phenotype. As shown in Figure 4, A and B, after 2 days of growth on solid medium, a time when colonies were conidiating profusely, the centers of the mutant colonies became darker than the centers of wild-type colonies. The expression of the mutant phenotype did not affect nor was it affected by conidial pigmentation, as yellow-spored $(y A 2)$ or white-spored (wA3), CAN41double mutants produced conidia of the expected colors in dark-centered colonies (data not shown). The CAN41

Figure 1. Developmental regulation of the CAN41 transcription unit. For the relevant wild type (FGSC26; for strain genotypes, see Table 1), RNA was extracted from hyphae grown in submerged culture (lane 1); developmentally induced cultures, containing hyphae, conidiophores, and mature conidia (lane 2); and purified conidia (lane 3). For the

\begin{tabular}{|c|c|c|c|c|c|c|c|c|}
\hline \multirow[b]{2}{*}{ PROBE } & \multicolumn{3}{|c|}{ WILD-TYPE } & \multirow{2}{*}{$\begin{array}{c}\text { brIA1 } \\
\text { INDUCED } \\
\text { CULTURE }\end{array}$} & \multirow{2}{*}{$\begin{array}{l}\text { abaA14 } \\
\text { INDUCED } \\
\text { CULTURE }\end{array}$} & \multirow{2}{*}{$\begin{array}{l}\text { WUTA6 } \\
\text { INDUCED } \\
\text { CULTURE }\end{array}$} & \multicolumn{2}{|c|}{$a / c A(p):: b r \mid A ; a b a A 14$} \\
\hline & HYPHAE & $\begin{array}{l}\text { INDUCED } \\
\text { CULTURE }\end{array}$ & CONIDIA & & & & GLUCOSE & THREONINE \\
\hline CAN41 & & e & & & e & e & & e \\
\hline rDNA & e. & ci & c & a: & *: & e. & * & - \\
\hline & 1 & 2 & 3 & 4 & 5 & 6 & 7 & 8 \\
\hline
\end{tabular}
mutants brlA1 (lane 4), abaA14 (lane 5), and wetA6 (lane 6), developmentally induced cultures contained hyphae and conidiophores that were arrested at successive stages of development. For ectopic expression of $b r l A$ in the absence of $a b a A$ and wet $A$ products, the strain TTA021, which contains the $b r l A$ structural gene fused to the $A$. nidulans alcohol dehydrogenase $I$ gene $(a l c A)$ promoter, was grown for $12 \mathrm{hr}$ in liquid medium containing glucose as a carbon source, harvested by filtration, and resuspended and incubated in liquid medium containing either glucose, an alcA-repressive carbon source, or threonine, an alcA-inductive carbon source. Cultures were grown at $37^{\circ} \mathrm{C}$ to inactivate the temperature-sensitive $a b a A 14$ product and thus the wetA gene (see Mirabito et al. 1989). RNA was harvested after $6 \mathrm{hr}$ of growth in either the alcA-repressive (lane 7) or alcA-inductive (lane 8) carbon source. Duplicate RNA samples $(2 \mu \mathrm{g})$ were spotted onto positively charged nylon membranes; the membranes were then dried, hybridized with a radiolabeled CAN41 or rDNA fragment, washed in $0.1 \times$ SSC, $0.1 \%$ SDS, at $68^{\circ} \mathrm{C}$, and subjected to autoradiography. Exposure times were 44 hr for the CAN41-hybridized membrane and $45 \mathrm{~min}$ for the rDNA-hybridized membrane. 
A

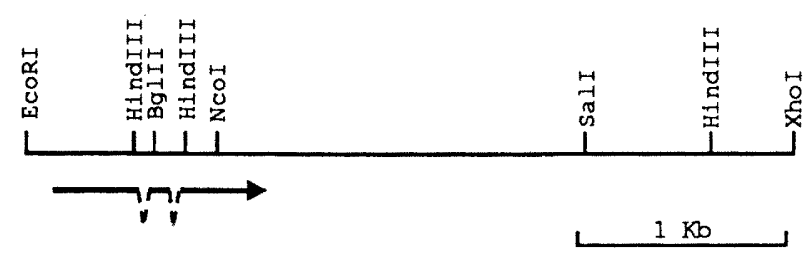

B

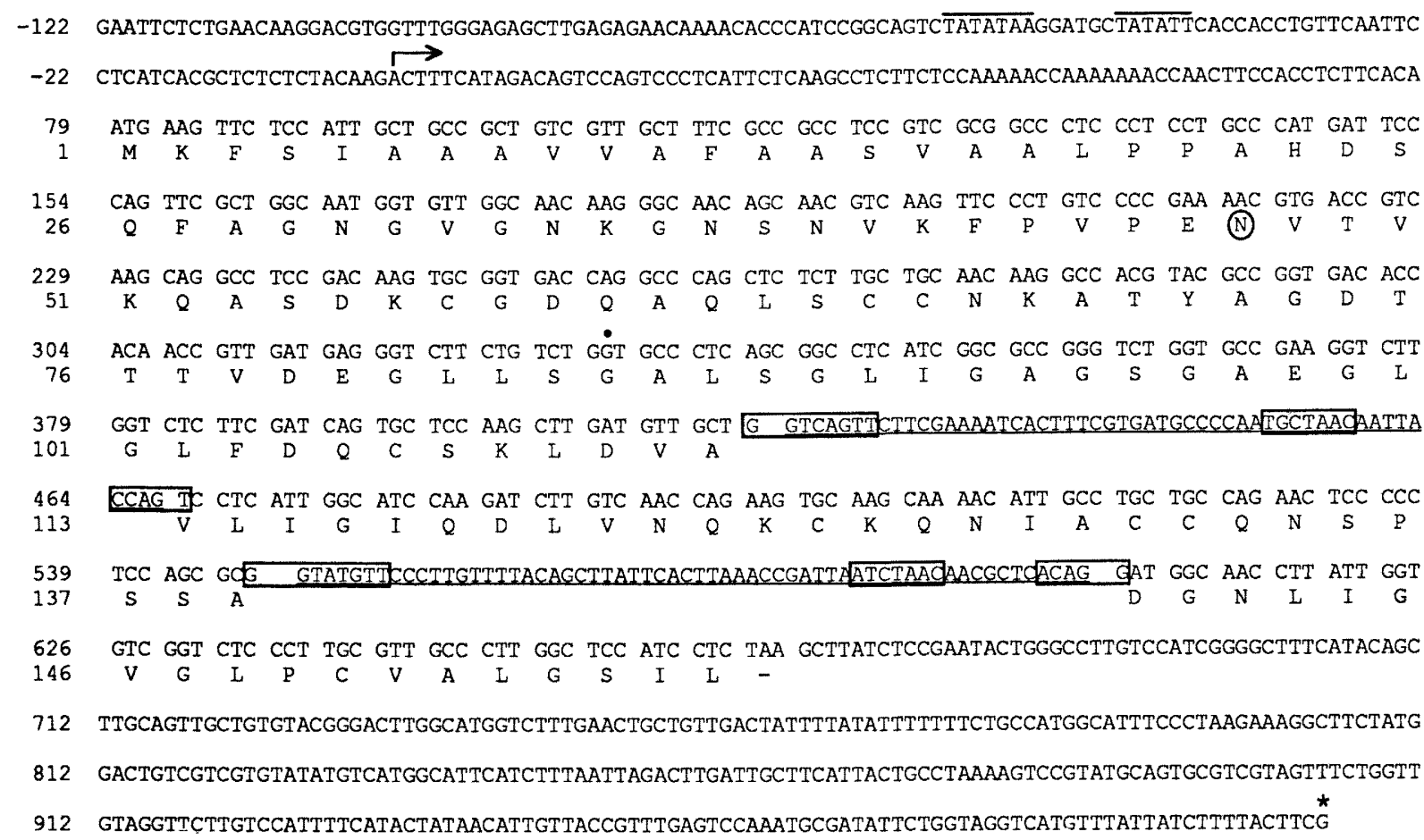

Figure 2. Transcriptional organization and sequence of the CAN41 locus. The pCAN41 cDNA clone was used to select a corresponding genomic clone, cosW16L5, from a cosmid library. An EcoRI-Xhol fragment encompassing the CAN41 transcription unit $|A|$ was restriction mapped, and the region encoding CAN41 mRNA was sequenced on both strands, as was the cloned cDNA insert $(B)$. Comparison of the cDNA and genomic sequences revealed the existence of two introns (underlined) containing consensus $A$. nidulans splice signals (boxed) (Ballance 1986). The transcription start site (arrow; +1 ) and the mRNA sequence upstream of the end of the cDNA insert (black dot) were determined by RNA sequence analysis with a primer corresponding to positions 375-392. The start site is preceded by two potential TATA boxes (overlined). The poly(A) addition site $\left({ }^{*}\right)$ was deduced from the cDNA sequence. The cDNA/mRNA sequence possesses an open translation reading frame beginning with the $5^{\prime}$-proximal methionine codon, which is taken to specify the RodA polypeptide and is given in one-letter code below the DNA sequence. A single potential $N$-glycosylation site exists at residue 47 (circled) (Devereux et al. 1984). The GenBank accession number is M61113.

heterozygous diploid (TMS017) appeared completely normal. Haploidization of this strain yielded approximately equal numbers of segregants with wild-type or CAN41 ${ }^{-}$phenotypes. Thus, the induced CAN41 mutation is fully recessive. Essentially identical results were obtained when the CAN41 gene was disrupted by homologous integration of a circular plasmid containing an internal restriction fragment of CAN41 /data not shown), confirming that loss of CAN41, and not adjacent DNA sequences, results in the mutant phenotype.

Microscopic examination of TMS015 revealed that the darkening of the colony was caused by the abnormal accumulation of liquid on the conidiophores. No cell lysis was apparent. Comparison of conidia from RMSO11 and TMS015 demonstrated that the spores of the transformant were less hydrophobic. Figure $4 \mathrm{C}$ shows that when mutant conidia were gently suspended in water they adhered to one another, remaining in columnar spore masses similar to those atop conidiophores. In contrast, as shown in Figure 4D, wild-type spores dispersed as individual spores or spore chains when suspended in water. Whereas CAN $41^{-}$conidia were readily wettable, wild- 
A

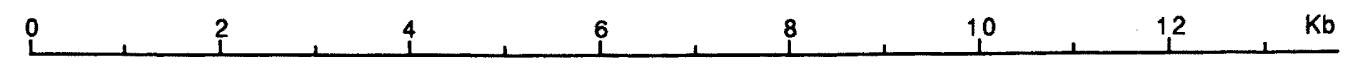

(1)

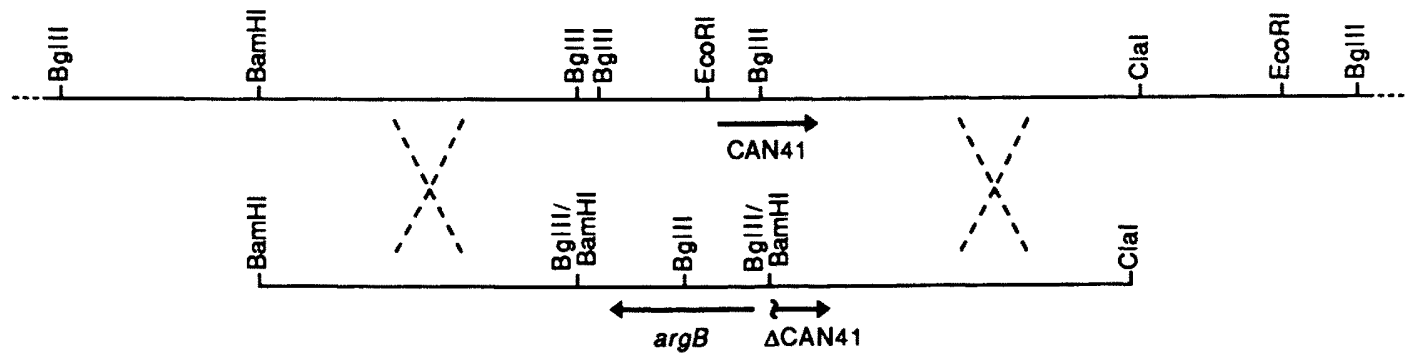

(3)

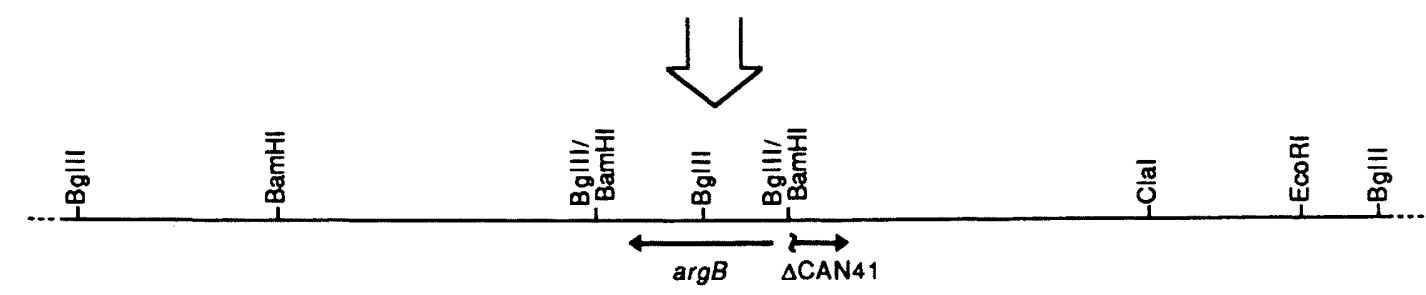

Figure 3. Inactivation of CAN41. (A) The CAN41 locus $(1)$ includes two BglII fragments (map position $5.4-7.3 \mathrm{~kb}$ ) corresponding to the $5^{\prime}$ half of the CAN4l transcription unit and $1.5 \mathrm{~kb}$ of nontranscribed upstream sequence. These fragments were removed from a $9.5-\mathrm{kb}$ $B a m H I-C l a I$ subclone and replaced with a $B a m H I$ fragment bearing the $A$. nidulans arg $B$ gene (2). The linear BamHI-ClaI fragment of the resulting construct was used to transform haploid (RMS011) and diploid (RMS012) strains from which the $\arg B$ locus had been deleted. The diagramed double crossover event produces the desired CAN41 mutation (3). (B) Haploid and diploid transformants (20 of each) were screened by Southern blot analysis for the desired integration event. Four haploids and one diploid (TMS017) appeared to contain the desired deletion/substitution mutation. One haploid (TMS015) was selected for further study. DNA from the recipients [RMS011 (n) and RMS012 (2n)] and transformants [TMS015 (n) and TMS017 (2n)| was digested with BglII or BamHI and EcoRI, fractionated in a $1 \%$ agarose gel, transferred to a nylon membrane, and hybridized with the CAN41 9.5-kb BamHI-ClaI fragment. The smallest BgIII restriction fragment from the wild-type locus is too small to be seen here. Sizes of bacteriophage $\lambda$ HindIII fragments are given in $\mathrm{kb}$.

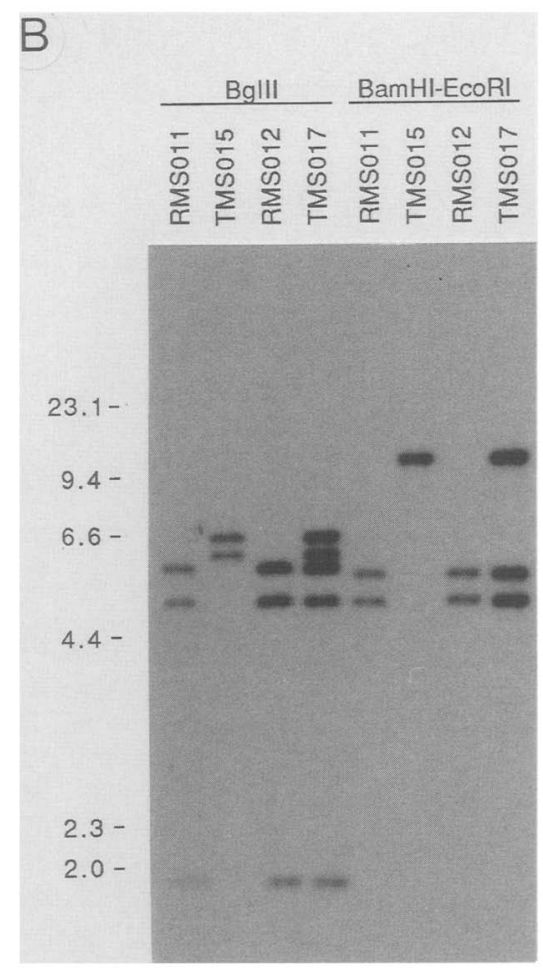

type conidia resisted suspension in water, often forming dry layers on the outer surfaces of water droplets. Comparison of the wild-type and CAN41- mutant by transmission electron microscopy (TEM), shown in Figure 4, $\mathrm{E}$ and $\mathrm{F}$, revealed that the mutant lacked the thin, proteinaceous, outer spore-wall layer, called the rodlet layer. Cole et al. (1979) observed an amorphous layer external to the rodlets in wild-type Aspergillus niger spores. However, we failed to detect such a layer in $A$. nidulans conidia (Fig. $4 \mathrm{~F}$ and $\mathrm{H}$ ). The absence of the rodlet layer in the mutant was especially apparent in replicas of freeze-fractured specimens, as shown in Figure 4, G and $H$. The abundant, parallel rodlets were arranged in irregularly oriented bundles that covered the surfaces of wild-type conidia and of two conidiophore cell types, the primary (metulae) and secondary (phialides) sterigmata of the conidiophore (Fig. 4H). These were absent in the mutant (Fig. 4G). 


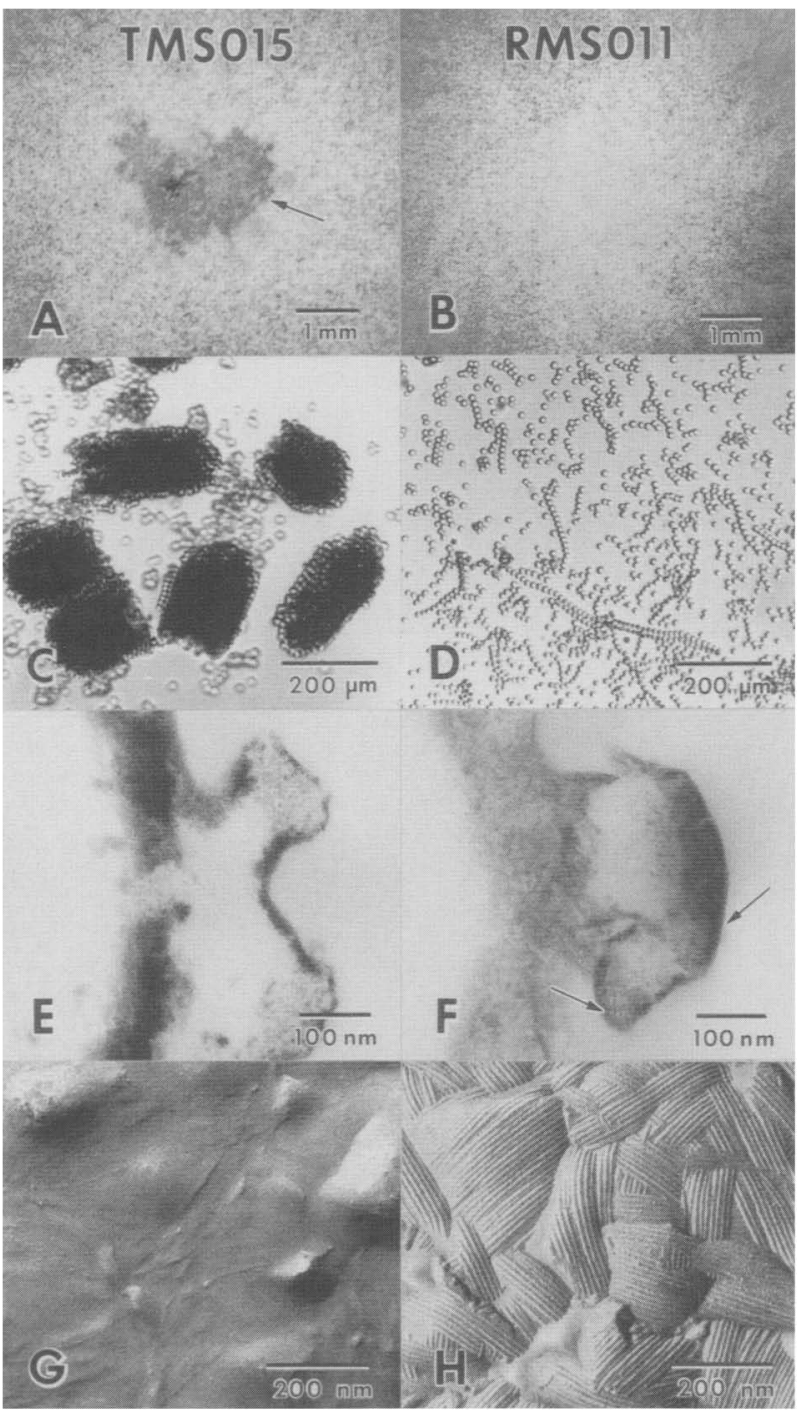

Figure 4. Phenotype of the CAN4l deletion strain. Photographs $A, C, E$, and $G$ are of CAN41- strain TMSOI5, and $B, D$, $F$, and $H$ are of CAN41 ${ }^{+}$strain RMSO11. $(A$ and $B)$ Individual colonies of RMS011 and TMS015 photographed after 2 days of growth at $37^{\circ} \mathrm{C}$. The CAN41- colony has a darkened central region (arrow) where water-soaked conidiophores have coalesced. $(C$ and $D)$ Free conidia suspended in water. CAN $41^{+}$ conidia disperse readily, whereas mutant conidia adhere to one another, forming cylindrical spore masses. $(E$ and $F)$ Cross sections of outer wall layers of conidia viewed by TEM. Rodlets, the dark-staining, regular structures indicated by arrows on the CAN $41^{+}$conidium, are absent from the CAN41- conidium. IG and $H$ ) Replicas of freeze-fracture surfaces of conidia. Parallel bundles of rodlets are apparent in the CAN41 ${ }^{+}$conidium but absent from the mutant conidium.

\section{Linkage of the CAN41 mutation and the rodletless phenotype}

To determine whether the mutant phenotype described in the previous section and the CAN41 disruption were linked, we crossed TMS015 with RMS010 (Table 1). As demonstrated in Figure 5, both of these strains are deleted for the $\arg B$ locus on chromosome III. TMSO15 contains a single copy of $\arg B^{+}$integrated into the genome at the CAN41 locus. Thus, all arginine-independent progeny from this cross must contain a copy of $\arg B$ integrated at CAN41, and all arginine-dependent progeny must contain an intact copy of CAN41. Of the 503 progeny scored, 257 were $\arg B^{+}$and had dark-centered colonies, and 246 were $\arg B^{-}$and had wild-type colonies; no recombinants were detected. Thus, the introduced mutation and the mutant phenotype are separated by $<0.5 \mathrm{cM}$.

\section{CAN41 is a new gene: rodA}

We refer to the phenotype of the CAN41 mutants as rodletless. To our knowledge, this phenotype had not been identified previously in $A$. nidulans. To confirm that the site-directed mutations identified a new locus, we mapped the mutation. We first established the chromosomal location of CAN41 by Southern blot analysis of CHEF-resolved chromosomes from the wild type and from a strain containing a reciprocal translocation between chromosomes V and VI (Käfer 1977; Brody and Carbon 1989). As shown in Figure 6, a CAN41-specific probe hybridized with the chromosome III + VI doublet in the wild type and with the chromosome III singlet in the translocation strain, permitting unambiguous assignment of the locus to chromosome III.

We crossed TMS015 with chromosome III mapping strain FGSC441 and detected linkage between rodletless and ActA and phenA, confirming the chromosome III assignment. The three separate crosses shown in Figure 7A were then used to map rodletless relative to the galA, carC, and Act A genes. As shown in Figure 7B, rodletless mapped between phen $A$ and $\operatorname{car} C$, a region containing no previously identified genes. We designated this new locus $\operatorname{rodA}$.

\section{Discussion}

We generated a new $A$. nidulans developmental mutant by targeting disruption of a transcription unit, designated CAN41, that was chosen for investigation simply because it showed strong developmental regulation. CAN41 transcript begins to accumulate during development at about the time sterigmata appear and remains at high levels throughout the final stages of conidiphore formation and during spore differentiation and maturation (Boylan et al. 1987). The observation that CAN41 transcript is present in conidiating cultures, but not in hyphae or mature conidia, implies that it accumulates specifically in conidiophore cells. This site of transcript accumulation is consistent with the observation that CAN41 is activated by the brlA early regulatory gene (Adams et al. 1988), which is expressed only in conidiophores (Aguirre et al. 1990). Disruption of CAN41 resulted in the loss of an outer cell wall layer, the rodlet layer, from three types of cells: metulae, phialides, and conidia. The rodletless phenotype had not been de- 
Table 1. A. nidulans strains

\begin{tabular}{|c|c|c|}
\hline Strain & Genotype & Source \\
\hline AJC472.1 & $y A 2$, biA1; wetA6; veA1, trpC399 & A.J. Clutterbuck \\
\hline FGSC4 & Glasgow wild type & Fungal Genetics Stock Center \\
\hline FGSC26 & biA1; veA1 & Fungal Genetics Stock Center \\
\hline FGSC40 & biA1; sA1; VeA1 $\mathrm{Tl}(\mathrm{V} ; \mathrm{VI})$ & Fungal Genetics Stock Center \\
\hline FGSC288 & $\begin{array}{l}\text { suA1adE20, yA2, adE20; wA3; galA1; pyroA4; facA303; } \\
\text { sB3; nicB8; veA1, riboB2 }\end{array}$ & Fungal Genetics Stock Center \\
\hline FGSC441 & $\begin{array}{l}\text { riboA1, proA1, biA1; wA3; sC12, galA1, ActA1, phenA2, } \\
\quad \text { suB4pro; veA1 }\end{array}$ & Fungal Genetics Stock Center \\
\hline JA015 & pabaA1, biA1; veA1, abaA14 & J. Aguirre \\
\hline MH1179 & wA3; carC17; pyroA4; veA1 & M.J. Hynes \\
\hline RMS010 & biA1; $\triangle \arg B:: \operatorname{trp} C \triangle B ;$ methG1; veA1, trpC801 & M.A. Stringer \\
\hline RMS011 & pabaA1, yA2; $\triangle a r g B:: \operatorname{trp} C \Delta B ;$ veA1, trpC 801 & M.A. Stringer \\
\hline RMS012 & $\begin{array}{l}\text { diploid: } \\
\text { biA1; } \arg B: \operatorname{trp} C \Delta B ; \text { meth } G 1 ; \text { veA1, trpC801 } \\
\text { pabaA1, yA2; } \arg B: \operatorname{trp} C \triangle B ; \operatorname{veA1} \operatorname{trpC} 801\end{array}$ & M.A. Stringer \\
\hline RMS023 & pabaA1, yA2; wA3; $\triangle a \operatorname{rg} B:: \operatorname{trp} C \Delta B ; v e A 1^{\mathrm{a}}$ & this study \\
\hline RMSO24 & riboA1, pabaA1, yA2; ActA1, $\operatorname{rod} A:: \arg B ; \operatorname{ve} A 1^{\mathrm{b}}$ & this study \\
\hline TMS015 & pabaA1, yA2; $\triangle \arg B:: \operatorname{trp} C \Delta B, \triangle \operatorname{rod} A:: a r g B ; \operatorname{veA1} \operatorname{trp} C 801$ & this study \\
\hline TMS017 & $\begin{array}{l}\text { diploid: } \\
\frac{\text { biA1; } \Delta a r g B:: \operatorname{trp} C \Delta B ; \text { methG1; veA1, } \operatorname{trp} C 801}{\text { pabaA1, yA2; } \Delta \arg B:: \operatorname{trp} C \Delta B ; \triangle \operatorname{rodA::argB;} \text { veA1 } \operatorname{trp} C 801}\end{array}$ & this study \\
\hline TTA021 & pabaA1, biA1; alcA $(\mathrm{p}):: b r 1 A ; a b a A 14$, veA1 & Adams et al. $\{1988\}$ \\
\hline
\end{tabular}

apartial genotype. May also contain galA1, trpC801, and proA1 and/or suB4pro.

'Partial genotype. May also contain galA1, $\triangle \arg B:: \operatorname{trp} C \Delta B$; trpC801, and proA1 and/or suB4pro.

scribed for A. nidulans prior to this study, and mapping of the mutant locus, here designated $\operatorname{rod} A$, confirmed that this gene had not been identified previously.

Fairly large $(>1 \mathrm{~cm})$ colonies of rod $A^{--}$mutants were easily distinguished from wild-type colonies due to the darkening of their centers where conidiophores had become water-soaked. However, smaller colonies were essentially indistinguishable from the wild type by direct visual examination. The failure of this aspect of the mutant phenotype to be expressed in small colonies probably explains why rodletless mutants were not identified in previous extensive screens for developmental mutants (Clutterbuck 1969, 1977). In these screens, colonies were plated at high densities under conditions that restricted colony growth to several millimeters, so the mutant phenotype would probably not have been apparent. The high density of colonies used in mutagenic screens can also lead to mutant remediation by "cross-feeding" of diffusible products produced by nearby nonmutants, as was observed for the Streptomyces mutant bld221 (Willey et al. 1991), which lacks a secreted peptide needed for aerial mycelium formation. However, cross-feeding is not likely to explain why $\operatorname{rod} A$ mutants were not identified previously, as $\operatorname{rod} A^{+} / \operatorname{rod} A^{-}$heterokaryons produced rodletless and normal conidiophores in close proximity to one another (M.A. Stringer and W.E. Timberlake, unpubl.). Our results and those from the study of the Streptomyces bld221 mutant reveal weaknesses in traditional screens for developmental mutants in micro-organisms. Not only are some mutants not easily identified in traditional screens, but some genes may not be susceptible to mutagenesis by classical techniques. For example, in
Saccharomyces cerevisiae, extensive screens for temperature-sensitive lethal mutations after the use of several mutagens detected only six essential genes on chromosome I. Subsequent deletion analysis of six transcription units within a small segment of the same chromosome identified three new essential genes (Diehl and Pringle 1991; Harris and Pringle 1991). These studies may, in part, explain the discrepancy between estimates obtained from classical and molecular techniques for the number of genes involved in development. These results also suggest that reverse mutagenesis will add substantially to the number and types of developmental mutants, providing novel insights into the mechanisms controlling microbial morphogenesis.

The observation that rodA is required for formation of the rodlet layer of conidia, even though the rodA transcript does not accumulate in conidia, places this gene in a growing class of genes, including the conidial pigmentation genes yA $\left(\mathrm{O}^{\prime} \mathrm{Hara}\right.$ and Timberlake 1989) and $w A$ (Mayorga and Timberlake 1990), that begin to be transcribed in the sporogenous phialides prior to spore formation, and whose products contribute directly to the formation of the specialized spore wall. Thus, the phialide, like the Bacillus spore mother cell (Losick et al. 1986), has a critical role in spore wall formation. We have observed that conidia produced in submerged culture (Adams et al. 1988) lack the rodlet layer and conidial laccase (T.C. Sewall, T.H. Adams, and W.E. Timberlake, unpubl.), the product of the $y A$ gene, even though both $y A$ and rod $A$ transcripts accumulate (Adams et al. 1988). These results suggest that outer spore wall components are secreted onto the surface of the nascent spore by the 


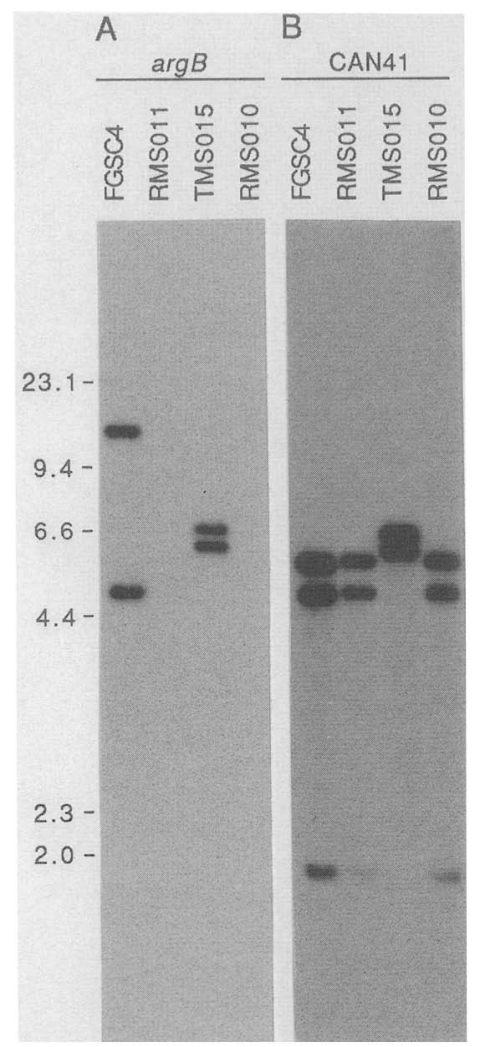

Figure 5. Linkage of $\arg B^{+}$to CAN41 ${ }^{-}$. DNA from a wild-type strain (FGSC4), the $\arg B$ deletion, transformation recipient strain (RMSO11), the CAN41 deletion strain (TMS015), and the $\arg B$ deletion strain to which TMS015 was crossed (RMS010) was digested with $B g I I I$ and subjected to Southern blot analysis. (A) The blot was hybridized with a DNA fragment containing the complete $\arg B$ gene. $(B)$ The blot in $A$ was stripped and rehybridized with the CAN41 9.5-kb BamHI-ClaI DNA fragment (see Fig. 3). Sizes of bacteriophage $\lambda$ HindIII fragments are given in $\mathrm{kb}$.

phialide. When spores are formed in the air, these components remain in place and become part of the cell wall matrix. In contrast, when spores are formed in an abnormal, aqueous environment, these components diffuse away and are lost from the wall.

Rodlet structures are a common feature of the aerial cells of filamentous bacteria and fungi (Cole et al. 1979). Beever and Dempsey (1978) reported that a rodletless (easily wettable) mutant of Neurospora crassa, an ascomycetous relative of $A$. nidulans, was deficient in the ability to disperse its conidia. The $A$. nidulans rodA mutant is also defective in spore dispersal, primarily due to adherence of the conidia to one another (see Fig. 4C) and liquid entrapment of conidia in the water-soaked centers of colonies. In A. nidulans, however, metulae and phialides, two nondispersed cell types that are not formed by Neurospora, normally possess rodlet layers that are absent in the mutant. It is possible that the rodlet layer on these cells contributes to spore dispersal by preventing water entrapment by the conidiophore or protects the cells from desiccation under conditions of low humidity, or both. We also observed rodlets on the surfaces of the conidiophore stalk and vesicle (T.C. Sewall and W.E. Timberlake, unpubl.). However, the stalk/vesicle rodlets were not arranged in a continuous layer but, instead, occurred singly, embedded in an amorphous matrix, and were not altered by rodA mutations. This result suggests that additional rodlet genes exist whose products are utilized in other aerial cell types.

Multiple genes encoding low-molecular-weight, hydrophobic, extracellular polypeptides, called hydrophobins, have been identified in the Holobasidiomycete S. commune. Schuren and Wessels (1990) described one gene, designated $S c 3$, that is expressed abundantly in both fruiting and nonfruiting cultures. Two related genes, $S c 1$ and $S c 4$, are expressed primarily during fruiting body development. The polypeptides encoded by these genes are secreted into the growth medium by submerged hyphae and accumulate in the cell walls of emerged hyphae. Wessels (1991) proposed that these proteins play a role in development of the aerial mycelium and formation of the fruiting bodies. One possibility is that these proteins diffuse away from submerged cells but polymerize in the walls of aerial cells, contributing to their hydrophobicity and structural rigidity. As shown in Figure 8A, there is significant sequence similarity between the Sc polypeptides and the predicted RodA polypeptide. Three shared features are particularly prominent. First, their amino termini resemble signal sequences, each with hydrophobic cores flanked by positively charged residues (Boyd and Beckwith 1990). This observation is in accord with the observed external

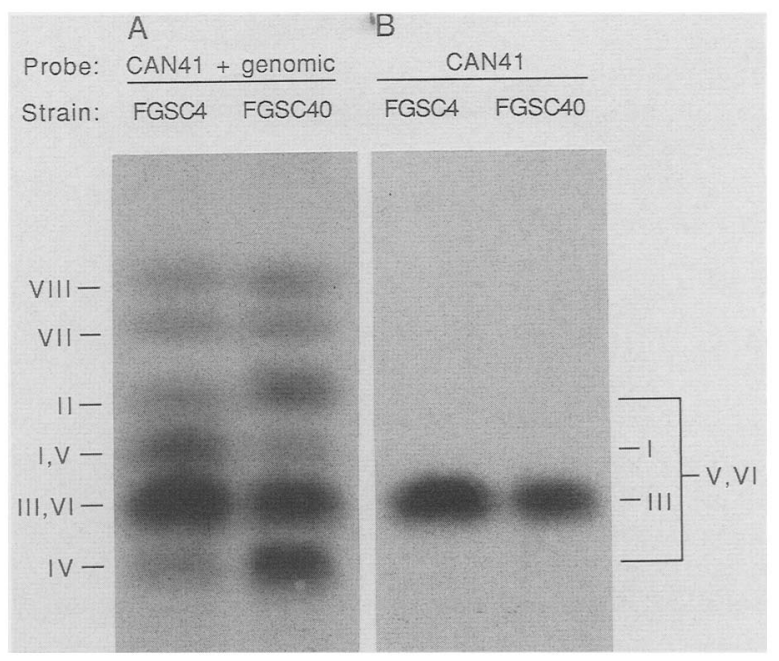

Figure 6. Assignment of CAN41 to chromosome III. A. nidulans chromosomes were isolated from FGSC4 and translocation strain FGSC40 [Tl (V; Vl)], fractionated by CHEF gel electrophoresis, and transferred to a nylon membrane. $(A)$ The blot was hybridized with a mixture of radiolabeled FGSC26 DNA and a CAN41-specific DNA fragment. $(B)$ It was then stripped and rehybridized with a CAN41-specific DNA fragment alone. Chromosomes are identified by Roman numerals. 
A

\begin{tabular}{|c|c|c|c|c|c|c|}
\hline \multirow[b]{2}{*}{ Cross } & \multicolumn{2}{|c|}{ Parental } & \multicolumn{2}{|c|}{ Recombinant } & \multirow[b]{2}{*}{$\begin{array}{c}\text { Total } \\
\text { Progeny }\end{array}$} & \multirow[b]{2}{*}{$\begin{array}{c}\text { Percentage } \\
\text { Recombinant }\end{array}$} \\
\hline & Genotype & $\begin{array}{c}\# \text { of } \\
\text { Progeny }\end{array}$ & Genotype & $\begin{array}{c}\text { \# of } \\
\text { Progeny }\end{array}$ & & \\
\hline $\begin{array}{c}\text { FGSC288 } x \\
\text { TMSO15 }\end{array}$ & $\begin{array}{l}\text { CAN41+, galA- } \\
\text { CAN41, galA }\end{array}$ & $\begin{array}{r}40 \\
121\end{array}$ & $\begin{array}{l}\text { CAN41+, galA+ } \\
\text { CAN41, galA }\end{array}$ & $\begin{array}{l}26 \\
15\end{array}$ & 202 & 20 \\
\hline $\begin{array}{c}\text { MH1179 x } \\
\text { TMS015 }\end{array}$ & $\begin{array}{l}\text { CAN41 } 1^{+}, \text {carC } \\
\text { CAN4 } 1^{-} \text {, } \text { carC }^{+}\end{array}$ & $\begin{array}{c}78 \\
181\end{array}$ & $\begin{array}{l}\text { CAN41+, } \text { carC }^{+} \\
\text {CAN } 41 ; \text {, } \text { carC }^{-}\end{array}$ & $\begin{array}{l}7 \\
7\end{array}$ & 273 & 5 \\
\hline $\begin{array}{c}\mathrm{RMSO}_{23} \mathrm{x} \\
\mathrm{RMSO} 24\end{array}$ & $\begin{array}{l}\text { CAN41 } 1^{+}, \text {ACtA } \\
\text { CAN41, ACtA }\end{array}$ & $\begin{array}{l}118 \\
147\end{array}$ & $\left\{\begin{array}{l}\text { CAN41+, ACtA } \\
\text { CAN4 } 1^{\circ}, \text { ACtA }\end{array}\right.$ & $\begin{array}{l}23 \\
16\end{array}$ & 304 & 13 \\
\hline
\end{tabular}

$\mathrm{B}$

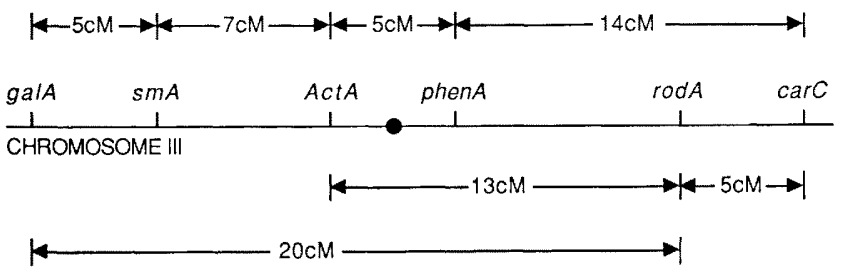

Figure 7. Mapping CAN4I on chromosome III. $\{A \mid$ Linkage of CAN41 to chromosome III markers galA, carC, and $A c t A$ was tested in the crosses given in the first column. Progeny from all crosses were scored visually for the CAN41 phenotype. Additionally, progeny from the cross FGSC288 $\times$ TMSO15 were tested for ability to utilize galactose as a sole carbon source; progeny from MH1179 $\times$ TMSO15 were tested for carboxin resistance; and progeny from RMS023 $\times$ RMS024 were tested for resistance to cycloheximide. The number of parental and recombinant progeny for each cross is shown. $|B|$ The position of CAN41 relative to galA, car $C$, and $A c t A$ is shown. Previously established map distances (uncorrected recombination percentages; Clutterbuck 1987) between relevant loci are given at top. The centromere.

location of the Sc polypeptides and indicates that RodA is also secreted. Given that the Aspergillus conidial rodlet layer is composed largely of protein (Cole et al. 1979; Claverie-Martin et al. 1986), it is probable that RodA is a rodlet component. The second prominent feature of these polypeptides is conservation of internal hydrophobic domains, as shown for RodA and Sc4 in Figure $8 \mathrm{~B}$. If $\mathrm{RodA}$ is a component of the rodlet layer, these domains may contribute directly to the hydrophobicity of the spore surface. The final common feature of these polypeptides is that they contain 8 cysteine residues arranged in the same pattern, including the conserved tripeptide CCN. The conservation of these cysteines may be indicative of an important role in the functions of these secreted, hydrophobic polypeptides. This could be the cross-linking of the polypeptides to form rodlets. Site-specific mutations in the rodA gene and biochemical and cytochemical analyses of the RodA polypeptide should help to relate polypeptide structure to function.

\section{Materials and methods}

Aspergillus strains, growth conditions, and genetics

The genotypes of the $A$. nidulans strains used in this study are given in Table 1. RMS023 and RMS024 are meiotic progeny of TMS015 and FGSC441. Standard A. nidulans genetic techniques were used (Pontecorvo et al. 1953; Clutterbuck 1974). To score for the rodletless mutation, strains were grown on agarsolidified medium for 2 days at $37^{\circ} \mathrm{C}$ in a humid incubator. Haploidization of the diploid TMS017 was aided by streaking spores onto a benomyl concentration gradient generated by covering a sloped layer of fully supplemented solid medium containing $1.5 \mu \mathrm{g} / \mathrm{ml}$ of benomyl (a gift from Dupont) with an equal amount of medium without benomyl.

All strains were grown in appropriately supplemented minimal medium with $\mathrm{NO}_{3}{ }^{-}$as nitrogen source (Käfer 1977). For RNA isolations, wild-type and developmental mutant strains were grown as described previously (Timberlake 1980; Adams and Timberlake 1990). The vegetative culture of FGSC26 was harvested after $22 \mathrm{hr}$ of submerged growth. For developmental RNA samples, strains were grown in submerged culture for 24 $\mathrm{hr}$ and harvested $25 \mathrm{hr}$ after developmental induction. For in- duction of the alcA $(\mathrm{p}):: b r l A$ gene, the procedures of Adams et al. (1988) were followed. abaA14 and wetA6 temperature-sensitive developmental mutants were grown at restrictive temperature $\left(37^{\circ} \mathrm{C}\right)$.

\section{Nucleic acid sequencing and protein sequence comparisons}

The cDNA clone pCAN41 and corresponding subclones of the genomic cosmid cosW16L5 were sequenced on both strands by using oligonucleotide primers in standard dideoxynucleotide chain-termination reactions (Sanger et al. 1977). The transcription start site was determined by RNA sequencing /Geliebter et al. 1986). Intron positions and a poly(A) addition site were inferred by comparison of the cDNA and mRNA sequences with the genomic sequence.

The predicted RodA protein sequence was compared with translated sequences from GenBank (release 66.0) and EMBL (release 25.0) and with protein sequences in the NBRF data base (release 21.0) by using the University of Wisconsin Genetics Computer Group programs TFASTA and FASTA (Devereux et al. 1984)

\section{Clone construction and $\mathrm{A}$. nidulans transformation}

Plasmids were constructed by using standard techniques (Sambrook et al. 1989|. Cloning and selection of pCAN41 have been described (Boylan et al. 1987). cosW16L5 was isolated from an ordered $A$. nidulans genomic library in pWE15 /Wahl et al. 1987; Brody et al. 1991), which is available from the Fungal Genetics Stock Center. pTA51 contains the EcoRI-Xhol fragment shown in Figure 2 cloned into pBluescript(M13)KS (Stratagene, La Jolla, CA). The plasmid used for deletion of $\operatorname{rodA}$, pMS18, was constructed from pMS14, a 9.5-kb BamHIClaI subclone from cosW16L5. Two adjacent BglII fragments containing the $5^{\prime}$ half of $\operatorname{rod} A$ and $1.5 \mathrm{~kb}$ of $5^{\prime}$-flanking sequence were replaced with a $1.8-\mathrm{kb} B a m H I$ fragment of pSalargB $(\mathrm{K}$. Miller and W.E. Timberlake, unpubl.), which contains the $A$. nidulans $\arg B$ gene. RMSO11 and RMS012 were transformed with a linearized 9.5-kb BamHI-EcoRV fragment from pMS18 by using standard techniques (Yelton et al. 1984).

\section{Nucleic acid isolation, blotting, and hybridization}

RNA and DNA were isolated as described by Timberlake (1986). DNA samples were digested with restriction enzymes, fraction- 
A

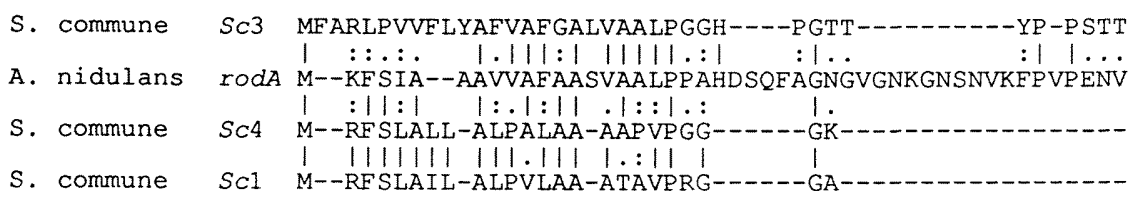

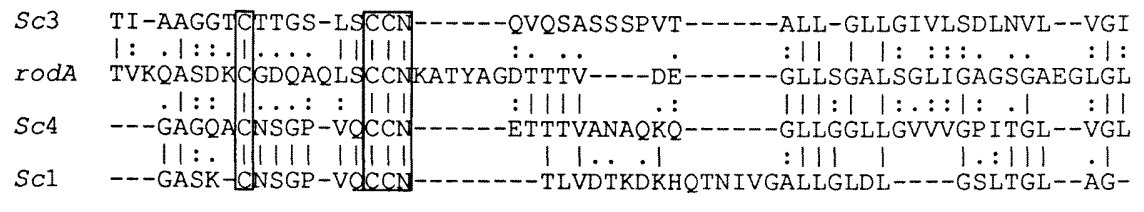

SC3 --SCSPLTV---IGV-GG--S-GCSAQTV-CCEN-TQE--NG-LINIG--CTPIN-IL 125

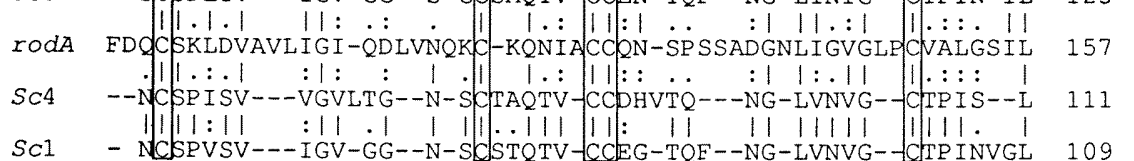

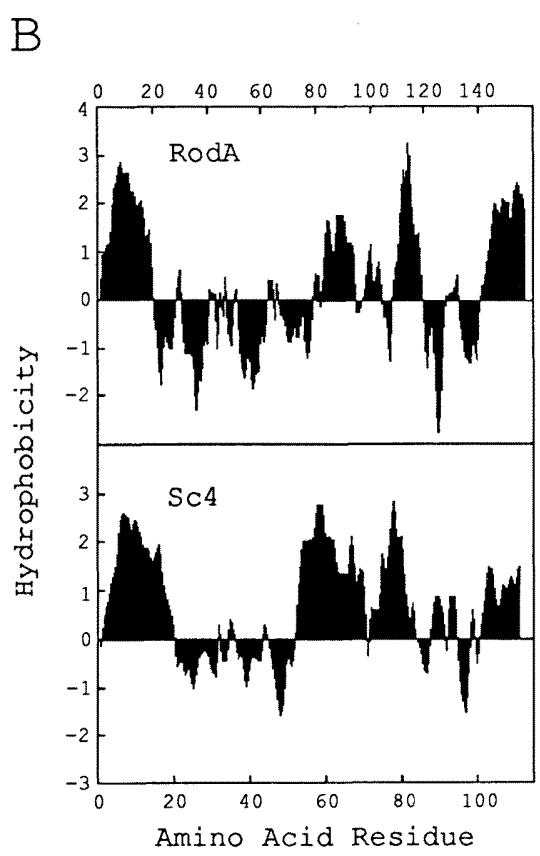

Figure 8. Comparison of the polypeptide sequences of $\operatorname{rod} A, S c 1, S c 3$, and $S c 4$. In $A$, the inferred rodA polypeptide sequence and those of $S$. commune Sc1, Sc3, and Sc4 polypeptides (Schuren and Wessels 1990) were first aligned at the 8 cysteine residues (boxed). The flanking and intervening residues were then aligned by using the GCG Gap program (Devereux et al. 1984). Amino acid identities are indicated by vertical bars, highly conserved substitutions by double dots, and less conserved substitutions by single dots between lines. Hydrophobicity plots $(B)$ of RodA and Sc4 were generated with the GCG Peptidestructure program (Devereux et al. 1984). The Kyte-Doolittle algorithm was used with a window size of 7 . Points above the $\mathrm{x}$-axis represent hydrophobic regions.

ated in agarose gels, and transferred to nylon membrane by standard procedures (Sambrook et al. 1989). RNA denatured in 50 $\mathrm{mM} \mathrm{NaOH}$ was applied directly to charged nylon membrane. Hybridization to ${ }^{32} \mathrm{P}$-labeled probes was performed according to procedures recommended by the membrane manufacturer. The EcoRI-NcoI fragment of pTA51 was used as a $\operatorname{rodA}$-specific probe (Figs. 1 and 6). A BamHI-SstII fragment from the $A$. nidulans rDNA repeat was used as an rDNA probe. The BamHIClaI insert of pMS14 was used as a probe for the rodA locus and flanking sequences. A BamHI-XbaI fragment from pMS12 (M.A. Stringer and W.E. Timberlake unpubl.) was used as an $\arg B$-specific probe.

Chromosomes were isolated, resolved by CHEF gel electrophoresis, and transferred to nylon membrane as described by Brody and Carbon (1989). For the mixed probe analysis of the CHEF gel blot, $1 \mu \mathrm{g}$ of FGSC26 total DNA and $\sim 0.1 \mu \mathrm{g}$ of $\operatorname{rod} A$-specific DNA fragment were nick-translated separately by the high-specific activity protocol recommended by BRL (Grand Island, NY). The blot was hybridized with $10^{5} \mathrm{cpm} / \mathrm{ml}$ of $\operatorname{rod} A$ DNA and $2 \times 10^{5} \mathrm{cpm} / \mathrm{ml}$ of total DNA.

\section{Microscopy}

Light micrographs of colonies were taken with a Nikon SMZ 2T stereoscopic microscope. Light micrographs of conidia suspended in a water droplet were photographed without a coverslip with a Nikon Optiphot photomicroscope. Conidia were prepared and examined by electron microscopy as described by Sewall et al. (1990).

For freeze-fracture, plates were flooded with $0.5 \%$ Triton X100 , and conidia and conidiophores were scraped from the colony surface with the edge of a microscope slide. Samples were filtered through $10 \mu \mathrm{m}$ of Nitex to separate conidia from conidiophores and centrifuged at $1000 \mathrm{~g}$. Concentrated conidia or conidiophores were fixed in $2.5 \%$ gluteraldehyde in $100 \mathrm{~mm}$ potassium phosphate buffer $(\mathrm{pH} 7.0)$ for $1 \mathrm{hr}$ and washed three times in buffer. Samples were cryoprotected by sequential infiltration with $10 \%(1 \mathrm{hr}), 20 \%(1 \mathrm{hr})$, and $30 \%$ (overnight) glycerol. Small droplets of conidia or conidiophores were placed on Balzer's specimen holders, frozen in liquid propane, and transferred to liquid nitrogen. Samples were fractured in a Balzer's BA360M unit, etched for $3 \mathrm{~min}$, and coated with platinum followed by carbon. Replicas were floated on a $50 \%$ glycerol solution (15 min) and transferred first to distilled water and then to $100 \%$ Clorox (overnight) to remove any remaining tissue. To avoid dispersing replicas, Clorox was diluted by removing half of the volume and replacing it with water three times. Replicas were then transferred to distilled water for 30-60 $\mathrm{min}$ and picked up on uncoated 300 mesh grids.

\section{Acknowledgments}

We thank Jan Westpheling and our colleagues in the laboratory for critical reviews of the manuscript, Kathy Vinson for her expert assistance in preparation of the manuscript, and Howard Brody for performing chromosome separations. This work was supported by U.S. Department of Agriculture grant 88-372623556 to Charles Mims and W.E.T., National Institutes of Health (NIH) grant GM-37886 to W.E.T., and NIH grant GM-42924 to W.E.T. and Jonathan Arnold. M.A.S. was supported by a University of Georgia Graduate Fellowship and by NIH-NRSA AIO7373.

The publication costs of this article were defrayed in part by 
payment of page charges. This article must therefore be hereby marked "advertisement" in accordance with 18 USC section 1734 solely to indicate this fact.

\section{References}

Adams, T.H. and W.E. Timberlake. 1990. Upstream elements repress premature expression of an Aspergillus developmental regulatory gene. Mol. Cell. Biol. 10: 4912-4919.

Adams, T.H., M.T. Boylan, and W.E. Timberlake. 1988. brlA is necessary and sufficient to direct conidiophore development in Aspergillus nidulans. Cell 54: 353-362.

Aguirre, J., T.H. Adams, and W.E. Timberlake. 1990. Spatial control of developmental regulatory genes in Aspergillus nidulans. Exp. Mycol. 14: 290-293.

Axelrod, D.E., M. Gealt, and M. Pastushok. 1973. Gene control of developmental competence in Aspergillus nidulans. Dev. Biol. 34: 9-15.

Ballance, D.J. 1986. Sequences important for gene expression in filamentous fungi. Yeast 2: 229-236.

Beever, R.E. and G.P.Dempsey. 1978. Function of rodlets on the surface of fungal spores. Nature 272: 608-610.

Boyd, D. and J. Beckwith. 1990. The role of charged amino acids in the localization of secreted and membrane proteins. Cell 62: $1031-1033$.

Boylan, M.T., P.M. Mirabito, C.E. Willett, C.R. Zimmerman, and W.E. Timberlake. 1987. Isolation and physical characterization of three essential conidiation genes from Aspergillus nidulans. Mol. Cell. Biol. 7: 3113-3118.

Brody, H. and J. Carbon. 1989. Electrophoretic karyotype of Aspergillus nidulans. Proc. Natl. Acad. Sci. 86: 6260-6263.

Brody, H., J. Griffith, A.J. Cuticchia, J. Arnold, and W.E. Timberlake. 1991. Chromosome-specific recombinant DNA libraries from the fungus Aspergillus nidulans. Nucleic Acids Res. (in press.)

Claverie-Martin, F., M.R. Diaz-Torres, and M.J. Geoghegan. 1986. Chemical composition and electron microscopy of the rodlet layer of Aspergillus nidulans conidia. Curr. Microbiol. 14: $221-225$.

Clutterbuck, A.J. 1969. A mutational analysis of conidial development in Aspergillus nidulans. Genetics 63: 317-327.

1974. Aspergillus nidulans. In Handbook of genetics (ed. R.C. King), pp. 447-510. Plenum Press, New York.

1977. The genetics of conidiation in Aspergillus nidulans. In Genetics and physiology of Aspergillus (ed. J.A. Pateman and J.E. Smith), pp. 305-317. Academic Press, New York.

1987. Aspergillus nidulans. In Genetic maps (ed. S.J. O'Brien), pp. 325-335. Cold Spring Harbor Laboratory, Cold Spring Harbor, New York.

Cole, G.T., S. Takashi, R. Kasai, T. Yokoyama, and Y. Nozawa. 1979. Surface ultrastructure and chemical composition of the cell walls of conidial fungi. Exp. Mycol. 3: 132-156.

Devereux, J., P. Haeberli, and O. Smithies. 1984. A comprehensive set of sequence analysis programs for the VAX. Nucleic Acids Res. 12: 387-395.

Diehl, B.E. and J.R. Pringle. 1991. Molecular analysis of Saccharomyces cerevisiae chromosome I: Identification of additional transcribed regions and demonstration that some encode essential functions. Genetics 127: 287-298.

Geliebter, J., R.A. Zeff, R.W. Melvold, and S.G. Nathenson. 1986. Mitotic recombination in germ cells generated two major histocompatibility complex mutant genes shown to be identical by RNA sequence analysis: $K^{b m 9}$ and $K^{b m 6}$. Proc. Natl. Acad. Sci. 83: 3371-3375.
Harris, S.D. and J.R. Pringle. 1991. Molecular analysis of Saccharomyces cerevisiae chromosome I: On the role of mutagen specificity in delimiting the set of genes identifiable using temperature-sensitive-lethal mutations. Genetics 127: 279-285.

Käfer, E. 1977. Meiotic and mitotic recombination in Aspergillus and its chromosomal aberrations. Adv. Genet. 19: 33131.

Losick, R., P. Youngman, and P.J. Piggot. 1986. Genetics of endospore formation in Bacillus subtilis. Annu. Rev. Genet. 20: 625-669.

Marshall, M.A. and W.E. Timberlake. 1991. Aspergillus nidulans wet $A$ activates spore-specific gene expression. Mol. Cell. Biol. 11: 55-62.

Martinelli, S.D. and A.J. Clutterbuck. 1971. A quantitative survey of conidiation mutants in Aspergillus nidulans. I. Gen. Microbiol. 69: 261-268.

Mayorga, M.E. and W.E. Timberlake. 1990. Isolation and molecular characterization of the Aspergillus nidulans $w A$ gene. Genetics 126: 73-79.

Mims, C.W., E.A. Richardson, and W.E. Timberlake. 1988. Ultrastructural analysis of conidiophore development in the fungus Aspergillus nidulans using freeze-substitution. Protoplasma 144: 132-141.

Mirabito, P.M., T.H. Adams, and W.E. Timberlake. 1989. Interactions of three sequentially expressed genes control temporal and spatial specificity in Aspergillus development. Cell 57: 859-868.

O'Hara, E.B. and W.E. Timberlake. 1989. Molecular characterization of the Aspergillus nidulans yA locus. Genetics 121: 249-254.

Oliver, P.T.P. 1972. Conidiophore and spore development in Aspergillus nidulans. I. Gen. Microbiol. 73: 45-54.

Orr, W.C. and W.E. Timberlake. 1982. Clustering of spore-specific genes in Aspergillus nidulans. Proc. Natl. Acad. Sci. 79: 5976-5980.

Pontecorvo, G., J.A. Roper, L.M. Hemmons, K.D. MacDonald, and A.W.J. Bufton 1953. The genetics of Aspergillus nidulans. Adv. Genet. 5: 141-238.

Sambrook, J., E.F. Fritsch, and T. Maniatis. 1989. Molecular cloning: A laboratory manual, 2nd ed. Cold Spring Harbor Laboratory Press, Cold Spring Harbor, New York

Sanger, F., S. Nicklen, and A.R. Coulson. 1977. DNA sequencing with chain- terminating inhibitors. Proc. Natl. Acad. Sci. 74: 5463-5467.

Schuren, F.H.J. and J.G.H. Wessels. 1990. Two genes specifically expressed in fruiting dikaryons of Schizophyllum commune: Homologies with a gene not regulated by mating-type genes. Gene 90: 199-205.

Sewall, T.C., C.W. Mims, and W.E. Timberlake. 1990. Conidium differentiation in Aspergillus nidulans wild-type and wet-white (wetA) mutant strains. Dev. Biol. 138: 499-508.

Timberlake, W.E. 1980. Developmental gene regulation in Aspergillus nidulans. Dev. Biol. 78: 497-510.

1986. Isolation of stage- and cell-specific genes from fungi. In Biology and molecular biology of plant-pathogen interactions. NATO ASI series, (ed. J. Bailey), Vol. H1, pp. 343-357. Springer-Verlag, Berlin.

1990. Molecular genetics of Aspergillus development. Annu. Rev. Genet. 24: 5-36.

Timberlake, W.E. and M.A. Marshall. 1989. Genetic engineering of filamentous fungi. Science 244: 1313-1317.

Wahl, G.M., K.A. Lewis, J.C. Ruiz, B. Rothenberg, J. Zhao, and G.A. Evans. 1987. Cosmid vectors for rapid genomic walking, restriction mapping, and gene transfer. Proc. Natl. Acad. Sci. 84: 2160-2164. 
Wessels, J.G.H. 1991. Fungal growth and development: A molecular perspective. In Frontiers in mycology (ed. D.L. Hawksworth). CAB International Mycological Institute. (In press.)

Willey, J., R. Santamaria, J. Guijarro, M. Geistlich, and R. Losick. 1991. Extracellular complementation of a developmental mutation implicates a small sporulation protein in aerial mycelium formation by Streptomyces coelicolor. Cell 65: 641-650.

Yelton, M.M., J.E. Hamer, and W.E. Timberlake. 1984. Transformation of Aspergillus nidulans by using a trpC plasmid. Proc. Natl. Acad. Sci. 81: 1470-1474.

Zimmermann, C.R., W.C. Orr, R.F. Leclerc, E.C. Barnard, and W.E. Timberlake. 1980. Molecular cloning and selection of genes regulated in Aspergillus development. Cell 21: 709715. 


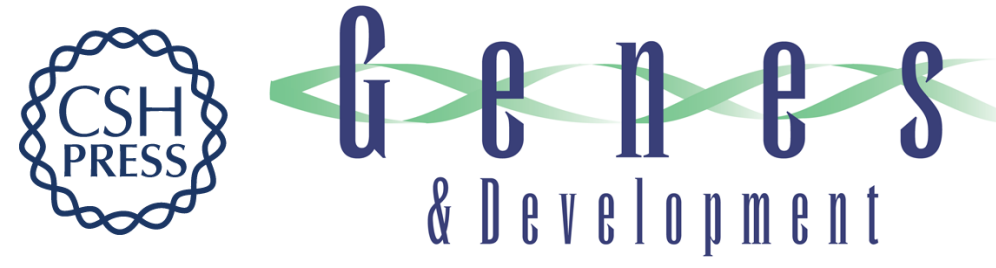

\section{Rodletless, a new Aspergillus developmental mutant induced by directed gene inactivation.}

M A Stringer, R A Dean, T C Sewall, et al.

Genes Dev. 1991, 5:

Access the most recent version at doi:10.1101/gad.5.7.1161

References This article cites 37 articles, 15 of which can be accessed free at: http://genesdev.cshlp.org/content/5/7/1161.full.html\#ref-list-1

License

Email Alerting

Service

Receive free email alerts when new articles cite this article - sign up in the box at the top right corner of the article or click here.

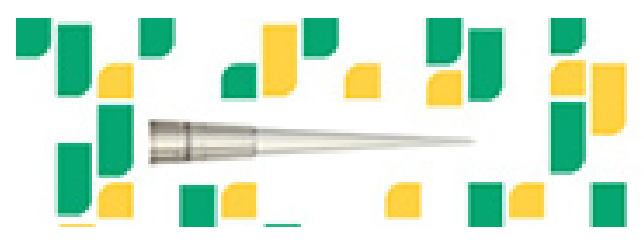

Focused on your science.

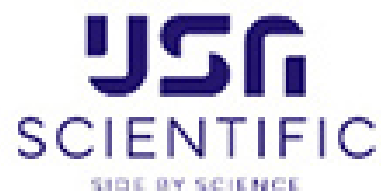

Copyright @ Cold Spring Harbor Laboratory Press 